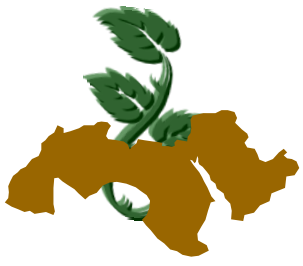

Arab Univ.

J. Agric. Sci., Ain Shams Univ., Cairo, 22(1), 93-106, 2014

\title{
TECHNICAL AND ECONOMIC EFFICIENCY OF SUGAR BEET PRODUC- TION IN SAHL EL TINA: USING DATA ENVELOPMENT ANALYSIS (DEA)
}

\author{
Sherine. F. Mansour ${ }^{1}$ and Soha M. Eldeep ${ }^{1}$ \\ 1- Agricultural Economic Dept., Socio-Economic Division, Desert Research Center, EL- \\ Mataria, Cairo Egypt
}

Keywords: Economic Efficiency, Sugar Beet, Data Envelopment Analysis

\section{ABSTRACT}

Sugar beet is an important crop that helps in establishing integrated agricultural-industrial societies, especially in the new reclaimed areas, it contributes in many industries such as sugar industry, and highly-value animal feed resulting from processing waste. Sahl El Tina had been chosen as it is one of the most important of the recent reclamation and aquaculture region depending on water of Al Salam Canal.

To achieve the target of increasing Production of sugar beet it became necessary to increase the efficient use of economic resources, and to achieve this objective study Data Envelopment Analysis (DEA) Approach had been used in order to estimate the technical and economic efficiencies allowing to reduce production costs and increase revenue, and thus support the expansion in the cultivation of the crop. The sample have 3 categories according to the area of the farm, the first category consists of 3 feddans or less, second category is more than 3 feddans and less than 7 feddans, the third category is more than 7 feddans to 10 feddans. The goal of the sample was to compare the efficiency of these categories, and recommended the optimum size of the farm.

\section{INTRODUCTION}

The achievement of self-sufficiency is considered an important national objective for its close relation with political, social and economic aspects under the present international variables and conventions. From the consumption point of view sugar comes after wheat as an essential and strategic commodity. Sugar is produced in Egypt from sugarcane $(61.2 \%)$ and, sugar beet $(38.8 \%)$ of the total local production which the beet-cultivated area reached to 399.3 thousand feddans by 2011 season, the total production was about 6.92 million tons. In Egypt sugarcane is considered the first

source for sugar production, molasses and sugar cane juice the popular beverage beside other uses, while sugar beet is the second source for sugar production. Its residues are processed and used as animal feeding beside other cultivate green crops Sugarcane cultivation consumes plenty of irrigation water, about $12400 \mathrm{~m} /$ feddan. That is why the expansion in sugar industry in Egypt depends now on the expansion in the cultivation of sugar beet, its area is about 249 thousand feddans i.e. about $3 / 4$ the area of sugarcane. Sahl El Tina area was chosen to be the point of research as it represents the most important cultivating and reclamation areas based on Al-Salam canal.

\section{Study Area}

Sahl El Tina was selected to represent marginal ecosystem. The irrigation water was obtained from mixed water (Nile water + drainage waters) of EI Salam Canal. The soils is characterized by severe salt affected, differ in depth and stratified profile layers. The soil salinity and salinity of irrigation water for these farms varied between 12.5 - 15.6 $\mathrm{dS} / \mathrm{m}$ and 1.6-2.3 dS/m (1000-1100 mg/L), respectively. The total area of the actual area of 35100 feddans by $70 \%$ of the total area, as an area of infrastructure and facilities 14900 feddans by $30 \%$ of the total area, consists region mainly from seven villages (1), (2), (3), (4), (5), (6), (7), region is characterized by growing traditional crops like (wheat, sugar beet, alfalfa, barley) may be due to the fact of the majority of the beneficiaries of those villages are from Kafr El-Sheikh, Elgharbia and Dakahlia governorates which are famous by planting traditional crops.

\section{Objective}

The research aimed to achieve the most efficient use of economic resources available to produce sugar beet in Sahl El Tina area, by measuring both the technical efficiency (TE), and economic efficiency (EE), determining the amount of resources that can achieve economic efficiency and estimate the surplus and deficit in the economic 
resources used in producing this crop, and assess the difference between the actual used quantities of resources and the optimum quantities that may achieve economic efficiency The research also aims to compare the categories of sugar beet farms most efficient to determine the optimum areas.

\section{Data and Methodology}

The field data collected from sample of beet grower's questionnaire in the concerned area in season 2012 - 2013. A questionnaire had been made through interviewing 250 of sugar beet growers in Sahl El Tina area. The growers were divided into three categories; the first category from 1 feddan to 3 feddans, second category from 3feddans to 7 feddans and third category from 7 feddans to 10 feddans, The purpose of questionnaire is to know the efficiency of available agricultural resources used by the various levels of sugar beet cultivated areas.

\section{Meaning of Efficiency}

The most common concept of efficiency is" technical efficiency" which means transferring physical inputs such as labour and capital into outputs at the best level of performance. TE is represented by a minimum combination of inputs necessary to produce specific level of outputs, and it measures the success of a firm to produce a maximum quantity of outputs from of a given set of inputs .Consequently, a firm is technically efficient when it cannot

increase any output or decrease any input without reducing any other outputs or increasing any other inputs.

It is necessary to mention that this concept of efficiency avoids the need to recourse the precise and the assumptions of weights which reflect the relative importance of the different inputs and outputs. But the existence of prices makes it able to discus another meaning of efficiency :

There is the "Allocative efficiency" which refers to choosing of inputs to the specific level of outputs at specific level of the prices, where the cost of production is minimum.

Another concept of efficiency is called "cost efficiency "or" Economic efficiency", which can be achieved when the firms find a combination of inputs that makes them able to produce the desired outputs at minimum cost .CE is the product or mixture of the technical and allocation efficiencies.

\section{The DEA methodology (Jill, 2006).}

There are two basic approaches to estimating a production function: the statistical (or econometric) approach and the non-statistical (or programming approach). Under the statistical approach, the production function can be represented by

$y_{k}=f\left(x_{1 k} ; \ldots ; x_{m k}\right) e^{-u k}$

where $y k$ is the output of producer $k$; $x_{i k}$ is the amount of the ith input $(i=1, \ldots, m)$ used by producer $k$; $u k \geq 0$ and uk represents the inefficiency of producer $\mathrm{k}$, and a specific distribution is assumed for the $u_{k}$.

Technical efficiency of firm $k\left(T E_{k}\right)$ is then measured by:

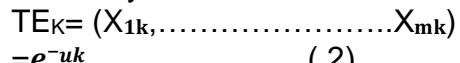

$=e^{-u k} \ldots \ldots \ldots \ldots \ldots \ldots . . . .(2)$

particular functional form for the production function is also assumed. Eq. (1) and hence the measures of inefficiency $\left(u_{k}\right)$ can be estimated using a variety of statistical techniques including corrected OLS, modified OLS and maximum likelihood estimation. (2) While these methods provide estimates of the parameters of the frontier, the significance of which can be tested, they are beset by the problem of possible misspecification, In addition, they are not easily applied in a situation where there are multiple inputs and multiple output.

DEA is a non-statistical and non-parametric approach which makes no assumptions regarding the distribution of inefficiencies or the functional form of the production function (although it does impose some technical restrictions such as monotonicity and convexity - see Fa" re, Grosskopf and Lovell, 1994). DEA is widely acclaimed as a useful technique for measuring efficiency, including production possibilities, which are deemed to be one of the common interests of Operational Research and Management Science Instead, it uses the input and output data themselves to compute ,using linear programming methods, the production possibility frontier. The efficiency of each unit is measured as the ratio of weighted output to weighted input, where the weights used are not assigned a priori, but are calculated by the technique itself so as to reflect the unit at its most efficient relative to all others in the dataset. In a multioutput, multi-input production context, DEA provides estimates of the distance function, which is a generalization of the single output production function. The advantages of the distance function approach are, first, that there is no need to make behavioral assumptions about the firms, such as cost minimization or profit maximization and, second, knowledge of input and output prices, in DEA regarding statistical distributions, however, means that there are no estimates or significance tests of the parameters of the production function, a potentially serious problem if results are sensitive to the specification of inputs and outputs. 


\section{DEA assumes constant returns to scale (CRS)}

Consider a simple example of five farmers $(A$, $\mathrm{B}, \mathrm{C}, \mathrm{D}, \mathrm{E})$ producing two outputs, $\mathrm{y}_{1}$ and $\mathrm{y}_{2}$ using the input $x$ (for example, the number of undergraduates). Fig. 1 plots the ratio of output $y_{1}$ to $x$ against the ratio of output $y_{2}$ to $x$, and the piecewise linear boundary which joins up farmers $A, B$, $C$ and $D$ is the production frontier. All DMUs on the frontier are efficient since none can produce more of both outputs (for a given input level) than any other unit on the frontier. In contrast, farmer E, which lies inside the frontier, is inefficient, and the ratio $O_{E} / O_{E O}$ measures farmer E's efficiency relative to the other DMUs in the data set.

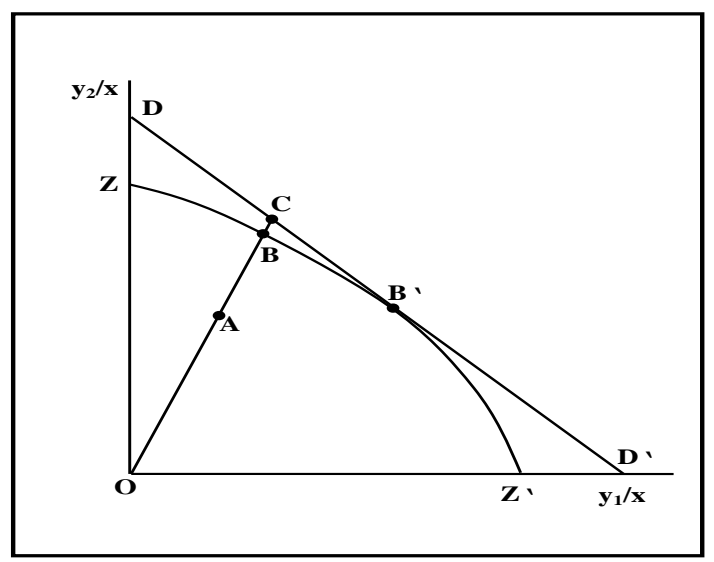

Fig. 1. DEA under variable returns to scale (VRS)

The CRS assumption can be relaxed and the DEA model can be easily modified to incorporate VRS (Banker, Charnes, and Cooper, 1984). While choice of orientation does not affect efficiencies under CRS, it does under the assumption of VRS (Coelli, Rao, and Battese, 1998), although it has been shown only to have a slight influence in many cases. In an input orientation, outputs are assumed to be fixed and the possibility of proportional reduction in inputs is explored, whereas, in an output orientation, it is inputs which are fixed while the possibility of a proportional expansion of outputs is explored. The latter orientation is deemed the more appropriate in this study where the quantity and quality of the inputs are fixed.

In an output-oriented framework and under the assumption of VRS, the following linear programming model needs to be solved for each DMU in the data set in order to calculate DEA efficiencies. Maximize $\emptyset_{\mathrm{k}}+\varepsilon \sum \mathrm{s}_{r} \mathrm{~s}_{r}=\mathbf{1}+\varepsilon \sum \boldsymbol{s}_{\boldsymbol{i}} \boldsymbol{m}_{i}=\mathbf{1} \ldots \ldots \ldots . .(3)$. subject to $\emptyset_{k} \mathrm{y}_{\mathrm{rk}}-\sum \lambda \boldsymbol{n}_{j}=\mathbf{1} \boldsymbol{i} \boldsymbol{y} \boldsymbol{r} \boldsymbol{j}+\boldsymbol{s}_{\boldsymbol{r}}=\mathbf{0}, \mathrm{r}=1, \ldots \ldots \ldots$, $\mathrm{s}, \ldots \ldots \ldots . . .(4)$.

$X_{i k}-\sum \lambda n_{r}=1 \mathrm{j} X_{i j}-S_{i}=0, i=1, \ldots \ldots ., m, \ldots \ldots \ldots(5)$. $\sum \lambda_{j} n_{j}=1=1$,

$\lambda_{\mathrm{j}}, \mathrm{Sr}_{\mathrm{r}}, \mathrm{Si}_{\mathrm{i}} \geq 0_{\mathrm{j}}=1, \ldots, \mathrm{n}_{\mathrm{r}}=1, \ldots, \mathrm{S} \mathrm{I}=1, \ldots . . \mathrm{m}$, where there are $s$ outputs and $m$ inputs; $y_{r k}$ is the amount of output $r$ used by DMU $k ; x_{i k}$ is the amount of input i used by $\mathrm{DMU}_{\mathrm{k}}$; and $\mathrm{S}_{\mathrm{r}}, \mathrm{S}_{\mathrm{j}}$ are the output and input slacks, respectively. Technical efficiency of DMU $k$ is measured by $1 / \varnothing_{k}$; $D M U_{k}$ is efficient if its efficiency score is 1 and all slacks are zero. The VRS dual differs from the CRS dual only by the inclusion of the constraint in Eq. (6). Comparison of the efficiencies derived from the above with the CRS efficiencies allows the derivation of measures of pure technical efficiency and scale efficiency.

\section{RESULTS AND DISCUSSION}

The research estimated scale efficiency of sugar beet in Sahl EI Tina and estimate technical efficiency under constant and variable return to scale, estimate economic efficiency and optimum use of the economic resources of the farm.

\section{Estimating economic scale efficiency for sugar beet in Sahl EI Tina}

Estimating scale efficiency for sugar beet and measuring technical efficiency under constant and variable return to scale required using data envelopment analysis (DEA)are explained afollows:

\section{Technical Efficiency}

The data collected from sample of 250 sugar beet growers, the growers were divided into three categories; the first category from 1 feddan to 3 feddans, second category from 3feddans to 7 feddans and third category from 7 feddans to 10feddans .

Estimating technical efficiency indicators under fixed and variable returns to scale at the level of the study are shown in Table (1). The average technical efficiency for the total sample under fixed return to scale, assuming that these farms were working in full capacity reached about 83 , what means that the same level of production could be achieved by using only $83 \%$ of the used resources and saving $17 \%$ of the resources without affecting the production level of sugar beet, thus the sample farms lose a part of its economic used resources which increased costs by $17 \%$.

While the average technical efficiency under variable return to scale assuming farms were not working in full capacity reached about 87this means that production could be achieved by using only $87 \%$ of the used resources and saving $13 \%$ of the resources idle, thus the sample farms lose a part of its economic used resources which will increase costs by $13 \%$,so the sample average 
Table 1. Technical standards of efficiency and return on Capacity sugar beet crop possessory groups in the area of Sahl Al-Tina

\begin{tabular}{|c|c|c|c|c|c|c|}
\hline category & $\begin{array}{c}\text { return to } \\
\text { scale }\end{array}$ & crste & vrste & scale & $\begin{array}{c}\text { number of } \\
\text { farms }\end{array}$ & $\%$ \\
\hline \multirow{6}{*}{ 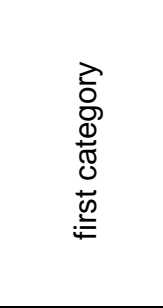 } & Drs & 0.861 & 0.873 & 0.987 & 20 & 22.5 \\
\hline & Irs & 0.789 & 0.864 & 0.913 & 44 & 49.4 \\
\hline & constant & 1 & 1 & 1 & 25 & 28.1 \\
\hline & average & 0.853 & 0.867 & 0.984 & 89 & 100 \\
\hline & Max & 1 & 1 & 1 & - & - \\
\hline & Min & 0.432 & 0.498 & 0.867 & - & - \\
\hline \multirow{6}{*}{ 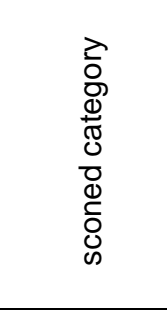 } & Drs & 0.832 & 0.851 & 0.978 & 14 & 16.5 \\
\hline & Irs & 0.712 & 0.853 & 0.835 & 42 & 49.4 \\
\hline & constant & 1 & 1 & 1 & 29 & 34.1 \\
\hline & average & 0.82 & 0.906 & 0.905 & 85 & 100 \\
\hline & Max & 1 & 1 & 1 & - & - \\
\hline & Min & 0.415 & 0.68 & 0.61 & - & - \\
\hline \multirow{6}{*}{ 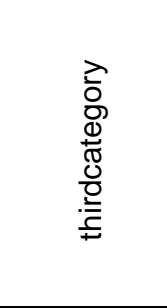 } & Drs & 0.823 & 0.845 & 0.974 & 9 & 12 \\
\hline & Irs & 0.797 & 0.878 & 0.908 & 37 & 49.3 \\
\hline & constant & 1 & 1 & 1 & 29 & 38.7 \\
\hline & average & 0.898 & 0.908 & 0.998 & 75 & 100 \\
\hline & Max & 1 & 1 & 1 & - & - \\
\hline & Min & 0.578 & 0.678 & 0.852 & - & - \\
\hline total sample & & 0.831 & 0.865 & 0.961 & 250 & - \\
\hline
\end{tabular}

Source: calculated from questionnaire data 2012.

efficiency under fixed return, the efficiency of the capacity achieved 96 , which means the possibility of reaching the same level of production by using $96 \%$ only of used resources and could save $4 \%$ of the resources without affecting the level of production.

\section{Technical efficiency for the First Category}

First category included 89 farms ranging in size from (1-3) feddans, under fixed return the technical efficiency ranged between $43 \%$ and $100 \%$ ,the average technical efficiency reached 85 , so the same level of production could be achieved by using only $85 \%$ of the used resources and saving $15 \%$ of the resources without affecting the level of production, otherwise, under variable return It is clear from Table (1) that the technical efficiency ranged between $50 \%$ and $100 \%$, the average achieved $87 \%$ and could save $13 \%$ of the resources without that affected the level of production, the efficiency of capacity for this category ranged between $87 \%$ and $100 \%$, the average effi- ciency of capacity was $98 \%$ that it could save $2 \%$ of the resources without affecting the level of production, so this category farms lose a part of its used economic resources in the production of sugar beet crop, resulting an increasing in production costs by $2 \%$.

As the results of the study, under declining the efficiency of capacity (Drs) in $22,5 \%$ of this category farms, the average fixed return to scale for those farms reached about $86 \%$, The average variable return to scale achieved about $87 \%$ and the average capacity efficiency reached about $99 \%$ which required reducing those farms production to achieve full technical efficiency, While under increasing the efficiency of capacity in $49.4 \%$ of this category farms, where the average fixed return to scale for those farms was $79 \%$ and the average variable return to scale reached $86 \%$ and the average capacity efficiency was $91 \%$, which required increasing these farms production to achieve full technical efficiency while there were about $28.1 \%$ of this category farms had achieved full technical efficiency and the efficiency of capaci- 
ty by reached one, these farms would continue at the same level of current production.

\section{Technical efficiency for the second Category}

Second category included 85 farms ranging in size from (3- 7) feddans, under fixed return the technical efficiency valid between $68 \%$ and $100 \%$ ,the average technical efficiency reached 82 , so the same level of production could be achieved by using only $82 \%$ of the used resources and saving $18 \%$ of the resources without affecting the level of production, otherwise, under variable return it is clear from Table (1) that the technical efficiency ranged between $68 \%$ and $100 \%$, the average achieved $91 \%$ and could save $9 \%$ of the resources without that affected the level of production, the efficiency of capacity for this category ranged between $61 \%$ and $100 \%$, the average efficiency of capacity was $91 \%$ that it could save $9 \%$ of the resources without affecting the level of production, so this category farms lose a part of its used economic resources in the production of sugar beet crop, resulting an increasing in production costs by $9 \%$.

As the results of the study, under declining the efficiency of capacity (Drs) in $16,5 \%$ of this category farms, the average fixed return to scale for those farms reached about $83 \%$, The average variable return to scale achieved about $85 \%$ and the average capacity efficiency reached about $97 \%$ which required reducing those farms production to achieve full technical efficiency, While under increasing the efficiency of capacity (Irs) in 49.4\% of this category farms, where the average fixed return to scale for those farms was $71 \%$ and the average variable return to scale reached $85 \%$ and the average capacity efficiency was $83 \%$, which required increasing these farms production to achieve full technical efficiency while there were about $34.1 \%$ of this category farms had achieved full technical efficiency and the efficiency of capacity by reached one, these farms would continue at the same level of current production.

\section{Technical efficiency for the third Category}

Third category included 75 farms ranging in size from (7- 10) feddans, under fixed return the technical efficiency valid between $58 \%$ and $100 \%$ ,the average technical efficiency reached 89 , so the same level of production could be achieved by using only $89 \%$ of the used resources and saving $11 \%$ of the resources without affecting the level of production, otherwise, under variable return it is clear from Table (1) that the technical efficiency had ranged between $68 \%$ and $100 \%$, the average achieved $91 \%$ and could save $9 \%$ of the resources without that affected the level of production, the efficiency of capacity for this category ranged between $85 \%$ and $100 \%$, the average efficiency of capacity was $99 \%$ that it could save $1 \%$ of the resources without affecting the level of production, so this category farms lose a part of its used economic resources in the production of sugar beet crop, resulting an increasing in production costs by $9 \%$.

As the results of the study, under declining the efficiency of capacity (Drs) in $12 \%$ of this category farms, the average fixed return to scale for those farms reached about $82 \%$, The average variable return to scale achieved about $85 \%$ and the average capacity efficiency reached about $97 \%$ which required reducing these farms production to achieve full technical efficiency, While under increasing the efficiency of capacity (Irs) in $49.3 \%$ of this category farms, where the average fixed return to scale for these farms was $79 \%$ and the average variable return to scale reached $88 \%$ and the average capacity efficiency was $91 \%$, which required increasing these farms production to achieve full technical efficiency while there were about $38 . \%$ of this category farms had achieved full technical efficiency and the efficiency of capacity reached one, these farms will continue in producing the same level of current production.

That is the third category was the best in using the agricultural resources technical efficiently comparing with the first and second categories, where the average efficiency of capacity for the third category was $99 \%$ on average about $98.4 \%$ and $90.5 \%$ for the first and second category, respectively, which requires more extension programs to raise the efficiency of the second category.

\section{2- Estimating Allocative and Economic effi- ciency for sugar beet in Sahl EI Tina}

\section{Estimating Allocative Efficiency}

The Allocative efficiency was estimated by using a (DEA) model under the prices or costs for the resources used in production, Table (2) showed that the average allocative efficiency for the total sample reached about $93 \%$ under fixed return to scale this means that reallocating the economic resources will save $7 \%$ of the production costs, Under variable return to scale the average allocative efficiency was $88 \%$ this means reallocating the economic resources will save $12 \%$ of the production costs.

\section{Allocative efficiency for the First Category}

Table (2) showed that the allocative efficiency of resources used for this category ranged between 0.767 and 0.983 , the average allocative efficiency was 0.835 under the fixed return to scale which means reallocating the economic resources will save $16.5 \%$ of the production costs in this cat- 
egory, Under the variable return to scale, the average allocative efficiency reached about 0.943 this means reallocating the economic resources will save $6 \%$ of the production costs.

\section{Allocative efficiency for the Second Category}

Table (2) showed that the allocative efficiency of resources used for this category ranged between 0.772 and 1 , the average allocative efficiency was 0.894 under the fixed return to scale which means that reallocating the economic resources will save $11 \%$ of the production costs in this category, Under the variable return to scale, the average allocative efficiency reached about 0.906 this means reallocating the economic resources will save $9 \%$ of the production costs.

\section{Allocative efficiency for the Third Category}

Table (2) showed that the allocative efficiency of resources used for this category ranged between 0.959 and 1 , the average allocative efficien- cy was 0.890 under the fixed return to scale which means that reallocating the economic resources will save $11 \%$ of the production costs in this category, Under the variable return to scale, the average allocative efficiency reached about 0.956this means the reallocating the economic resources will save $4 \%$ of the production costs.

That is the third category was the best in using the agricultural resources allocative efficiently comparing with the first and second categories.

\section{Estimating Economic Efficiency}

Table (2) showed that the average economic efficiency for the total sample reached about 0.722 under fixed return to scale where the same level of production could achieved under reduction the costs by $27 \%$ from the production costs, Under variable return to scale the average economic efficiency was 0.811 where the same level of production could achieved under reduction the costs by $19 \%$ from the production costs.

Table 2. The economic efficiency of groups sample study in Sahl Al-Tina

\begin{tabular}{|c|c|c|c|c|c|c|c|c|c|}
\hline & \multicolumn{2}{|c|}{ category } & $\begin{array}{c}\text { number } \\
\text { of } \\
\text { farms }\end{array}$ & $\begin{array}{c}\text { constant } \\
\text { scale }\end{array}$ & $\begin{array}{c}\text { variable } \\
\text { scale }\end{array}$ & $\begin{array}{c}\text { constant } \\
\text { scale }\end{array}$ & $\begin{array}{c}\text { variable } \\
\text { scale }\end{array}$ & $\begin{array}{l}\text { con- } \\
\text { stant } \\
\text { scale }\end{array}$ & $\begin{array}{c}\text { variable } \\
\text { scale }\end{array}$ \\
\hline \multirow{3}{*}{ 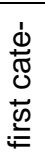 } & \multirow{3}{*}{$\begin{array}{l}\text { ̇̀ } \\
\text { वे }\end{array}$} & average & & 0.822 & 0.897 & 0.835 & 0.943 & 0.687 & 0.787 \\
\hline & & Max & 89 & 1 & 1 & 0.983 & 1 & 0.983 & 1 \\
\hline & & Min & & 0.51 & 0.597 & 0.767 & 0.705 & 0.391 & 0.547 \\
\hline \multirow{3}{*}{$\begin{array}{l}\text { ర్ } \\
\stackrel{0}{0} \\
\text { ¿ }\end{array}$} & \multirow{3}{*}{ 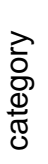 } & average & & 0.819 & 0.903 & 0.894 & 0.906 & 0.732 & 0.81 \\
\hline & & Max & 85 & 1 & 1 & 1 & 1 & 1 & 1 \\
\hline & & Min & & 0.394 & 0.732 & 0.772 & 0.811 & 0.304 & 0.626 \\
\hline \multirow{3}{*}{ 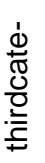 } & \multirow{3}{*}{ 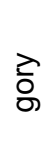 } & average & & 0.848 & 0.901 & 0.89 & 0.956 & 0.755 & 0.851 \\
\hline & & Max & 75 & 1 & 1 & 1 & 1 & 1 & 1 \\
\hline & & Min & & 0.567 & 0.744 & 0.959 & 0.66 & 0.544 & 0.633 \\
\hline \multirow{3}{*}{ 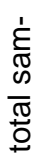 } & \multirow{3}{*}{$\frac{0}{2}$} & average & & 0.779 & 0.867 & 0.927 & 0.875 & 0.722 & 0.811 \\
\hline & & Max & 250 & 1 & 1 & 1 & 1 & 1 & 1 \\
\hline & & Min & & 0.396 & 0.524 & 0.74 & 0.943 & 0.333 & 0.494 \\
\hline
\end{tabular}

Source: calculated from questionnaire data 2012.

\section{First Category Economic Efficiency}

The economic efficiency for this category ranged between 0.391 and 0.983 , the average Economic efficiency was 0.69 under the fixed return to scale. This means the same level of production could achieved under reduction the production costs by $30 \%$. Under the variable return to scale. The economic efficiency of resources ranged between 0.541 and 1 , the average Economic efficiency reached about 0.787 , this means that the same level of production could reached by reducing the costs by $21 \%$.

\section{Second Category Economic Efficiency}

The economic efficiency for this category ranged between 0.304 and 1, the average Eco- 
nomic efficiency was 0.73 under the fixed return to scale, This means the same level of production could achieved under reduction the production costs by $27 \%$. Under the variable return to scale, The economic efficiency of resources ranged between 0.626 and 1 , the average Economic efficiency reached about 0.810 , this means that the same level of production could reached by reducing the costs by $19 \%$.

\section{Third Category Economic Efficiency}

The economic efficiency for this category ranged between 0.544 and 1, the average Economic efficiency was 0.76 under the fixed return to scale, This means the same level of production could achieved under reduction the production costs by $24 \%$. Under the variable return to scale, The economic efficiency of resources ranged between 0.633 and 1 , the average Economic efficiency reached about 0.851 , this means that the same level of production could reached by reducing the costs by $15 \%$.

So the third category was the best in using the agricultural resources economic efficiently comparing with the first and second categories under fixed and variable return to scale.

\section{3- The optimal use for the economic resources in the sample farms}

Knowing price or the unit cost for the actual amount of resources combinations helps to estimate the economic efficiency, it is the combination which cost constraint touch envelope data (possibilities production frontier), at this point the efficient use of resources is achieved, from Tables $(2,3)$ results, it becomes possible to use the averages of categories economic efficiency in estimating the optimal amount of resources.

The amount of resources which achieved economic efficiency under fixed return to scale

Table (3) showed that, when compared the average actual cultivated area on the level of the sample by others which achieved economic efficiency it is necessary to reduce the average size of 5.4 feddans to 4.15 feddans, where the amount of surplus about $23.15 \%$, It also requires reducing the actual quantities of fertilizer, number of machine work hours, labour, the amount of chemical fertilizers and quantity of seeds by $23.27 \%, 34.39 \%$, $27.07 \%, 25.39 \%, 21.37 \%$ respectively, In order to achieve economic efficiency by $72 \%$. the sample categories have to reduce the actual quantities of resources used as the average actual area by $41.20 \%, 15 \%, 20 \%$ First, second and third category respectively, in order to achieve full economic efficiency. but in the first category requires to in- crease the average of fertilizer used.

By $2.50 \%$, reduce the average amount of fertilizer by $27.85 \%, 33.21 \%, 23.27 \%$ second and third categories, reduce the average number of machine work hours by $28.26 \%, 45.89 \%, 29.79 \%$ first, second and third categories, reduce the average human work by $36.68 \%, 23.69 \%, 26.63 \%$ first, second and third categories, reduce the average of chemical fertilizers by $45.1 \%, 26.34 \%, 20$. 3\% first, second and third categories and reduce the average quantity of seeds by $6.67 \%, 23.81 \%, 17$. $14 \%$ first, second and third categories respectively in order to achieve full economic efficiency.

The amount of resources which achieved economic efficiency under variable return to scale

Table (4) showed that, when compared the average actual cultivated area on the level of the sample by others which achieved economic efficiency it is necessary to reduce the average size of 5.4 feddans to 4.9 feddans, where the amount of surplus about $8.15 \%$, It also requires reducing the actual quantities of fertilizer, number of machine work hours, labour, the amount of chemical fertilizers and quantity of seeds by $25.48 \%, 29.98 \%$, $9.53 \%, 20.6 \%, 18.62 \%$ respectively, In order to achieve economic efficiency by $81 \%$.the categories of the sample have to reduce the actual quantities of resources used as the average actual area by $13.64 \%, 14.29 \%$, for First, second categories respectively and increase the average actual area for third category by $1.09 \%$, reduce the average of fertilizer by $16.96 \%, 33.22 \%$ second and third categories, reduce the average number of machine work hours by $33.33 \%, 30.78 \%, 40.68 \%$ first, second and third categories, reduce the average human work by $25.96 \%, 14.26 \%, 24.41 \%$ first, second and third categories, reduce the average of chemical fertilizers by $55.67 \%, 14.39 \%, 15.18 \%$ first, second and third categories and reduce the average quantity of seeds by $13.33 \%, 28.57 \%, 17$. $14 \%$ first, second and third categories respectively in order to achieve full economic efficiency.

\section{CONCLUSION}

Sugar beet is an important crop that helps in establishing integrated agricultural-industrial societies, especially in the new reclaimed areas. Sahl El Tina had been chosen as it is one of the most important reclaimed area and as aquaculture region depending on water of Al Salam Canal. The research aimed at achieving the most efficient use of economic available resources to produce sugar beet in Sahl El Tina area, Data Envelopment Analysis (DEA) Approach was used in order to estimate the technical and economic efficiencies allowing to reduce production costs and increase revenue, the sample was divided into 3 categories according to 
farm area, the first category was 3 feddans or less, second category was more than 3 feddans to less than 7 feddans, the third category was more than 7 feddans to 10 feddans. The objective of dividing the sample was to compare the efficiency between these categories, and recommended the optimum size of the farm.

The results of the study showed that the technical efficiency under fixed return to scale reached $89 \%$ for the third category, while it was about $85 \%$ , $82 \%$ for the first and second categories respectively. With the assumption of variable return to scale, technical efficiency was about $90.8 \%$ for the third category, $86.7 \%$ and about $90.6 \%$ for the first and second categories, respectively. The economic efficiency for the categories showed that, the third category was more than the second category by $2.3 \%, 4.1 \%$ and more than the first category by $6.8 \%, 6.4 \%$ under fixed and variable return to scale, respectively. The second category exceeds the first one by $4.5 \%, 2.3 \%$ under fixed and variable return to scale, respectively, under fixed return to scale when compared the average actual cultivated area at the level of the total sample by others which achieved economic efficiency it is necessary to reduce the average size by $23.15 \%$, It also requires reducing the actual quantities of fertilizer, number of machine work hours, labour, the amount of chemical fertilizers and quantity of seeds by $23.27 \%, 34.39 \%, 27.07 \%, 25.39 \%, 21.37$ $\%$ respectively, In order to achieve economic efficiency by $72 \%$. under variable return to scale when comparing the average actual cultivated area at the level of the total sample by others which achieved economic efficiency it is necessary to reduce the average size by $8.15 \%$, It also requires reducing the actual quantities of fertilizer, number of machine work hours, labour, the amount of chemical fertilizers and quantity of seeds by $25.48 \%, 29.98 \%, 9.53 \%, 20.6 \%, 18.62 \%$ respectively, In order to achieve economic efficiency by $81 \%$. that means the same level of production can be achieved at a lower cost by $19 \%$.

\section{RECOMMENDATIONS}

1- The study recommends that, according to the capacity efficiency reducing production in $22 \%$ of First Category of holders farms , $16.5 \%$ and $12 \%$ in the second and third category respectively to achieve full technical efficiency, It also recommends increasing the farms production for first, second, third category by $49.4,49.4$, $49.3 \%$ respectively to achieve full technical efficiency, which need to intensify the efforts of agricultural extension to help these categories possessory to achieve full technical efficiency.
2- re-examination the farms policies productivity in the second category holders, which achieved the lowest average technical efficiency under fixed return to scale and price efficiency to increase its production .

3-using scientific methods to manage sugar beet farms in the three categories and re- allocation the resources in order to achieve the same level of current production under reducing Costs by $31 \%, 27 \%, 25 \%$ for first , second and third category respectively.

4-maximizing utilization from the amount of extra economic resources used in cultivating sugar beet by using these extra resources for other crops.

\section{REFERENCES}

Abbott, M., and Doucouliagos, C. (2003). The efficiency of Australian universities: a data envelopment analysis. Economics of Education Review, 22(1): 89-97.

Aigner, D.J.; Lovell, C.A.K. and Schmidt, P. (1997). Formulation and estimation of stochastic frontier production function models'. Journal of Econometrics, 6(1): 21-37.

Athanassopoulos, A.D. and Shale, E. (1997). Assessing the comparative efficiency of higher education institutions in the UK by means of data envelopment analysis. Education Economics, 5(2): 117-134.

Avkiran, N.K. (2001). Investigating technical and scale efficiencies of Australian universities through data envelopment analysis. SocioEconomic Planning Sciences, 35(1): 57-80.

Banker, R.D. (1996). Hypothesis tests using data envelopment analysis. Journal of Productivity Analysis, 7: 139-159.

Banker, R.D.; Charnes, A. and Cooper, W.W. (1984). Some models for estimating technical and scale inefficiencies in data envelopment analysis. Management Science, 30(9):10781092.

Coelli, T., Rao, D.S. and Battese, G.E. (1998). An introduction to efficiency and productivity analysis. Norwell, Massachusetts:Kluwer Academic, USA.

Cubbin, J., and Tzanidakis, G. (1998). Regression versus data envelopment analysis for efficiency measurement: An application to the England and Wales regulated water industry. Utilities Policy, 7: 75-85.

Fa" re, R., Grosskopf, S. and Lovell, C.A.K. (1994). Production frontiers. Cambridge: Cambridge University Press. Farrell, M. The measurement of productive efficiency. Journal of the Royal Statistical Society, Series A, 120: 253-281. 
Jill Johnes (2006). Data envelopment analysis and its application to the measurement of efficiency in higher education. Economics of Education Review, 25: 273-288.

Ra“ ty, T. (2002). Efficient facet based efficiency index: $A$ variable returns to scale specification. J. Productivity Analysis, 17: 65-82.
Ruggiero, J. (1996). On the measurement of technical efficiency in the public sector. European. J. Operational Research, 90: 553-565.

W., and Rhodes, E. (1981). Evaluating program and managerial efficiency: An application of DEA to program follow-through. Management Science, 27(6): 668-697. 